\title{
Evaluation of Fine Needle Aspiration Cytology (FNAC) in Diagnosis of Papulo-Nodular Skin Lesion
}

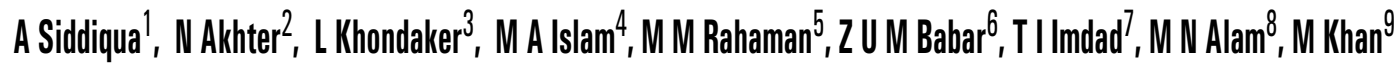

1 Dr. Ayesha Siddiqua Specialist in Dermatology \& Venereology

Bangabandhu Sheikh Mujib

Medical University (BSMMU), Dhaka

${ }^{2}$ Professor ( Dr.) Nargis Akhtar

3 Dr. Lubna Khondaker

Assistant Professor

${ }^{4}$ Dr. Md Aminul Islam.

Assistant Professor

Dept. of Dermatology \& Venereology NIMC, Dhaka

${ }^{5}$ Dr. Md. Mahabubur Rahaman. Consaltant Dermatologist Comilla Medical Center

${ }^{6}$ Dr. Zahir Uddin Muhammad Babar

7Dr. Tawhidul Islam Imdad Junior Consultant Dept. of Dermatology \& Venereology Jalalabad Ragib Rabeya Medical College, Sylhet

${ }^{8}$ Dr. Mohd. Nurul Alam

9 Dr. Mesbahuddin Khan

Assistant Professor

Dept. of Dermatology \& Venereology Diabetic Association Medical College Hospital, Faridpur

\section{$2,3,6,8$}

Dept. of Dermatology \& Venereology BSMMU, Dhaka

Correspondence

Dr Ayesha Siddiqua

Specialist in Dermatology

\& Venereology, BSMMU

\section{Abstract}

Objective : The objective of this study was to evaluate the accuracy of Fine Needle Aspiration Cytology (FNAC) in diagnosis of Papulo. nodular skin disease.

Methodology : This prospective study was carried out in Bangabandhu Sheik Mujib Medical University (BSMMU) in the department of Dermatology and Veneral disease and department of Pathology. Study period was March 2012 to August 2012 (six months). Thirty (30) patients with papulonodular skin lesion for more than 6 weeks were enrolled. Data were collected and analysis was done by using SPSS.

Results : Among 30 patients, 14 cases which were histopathologically diagnosed as epidermal inclusion cyst, pilar cyst, lipoma were also diagnosed positive by FNAC and accuracy were $100 \%$. Rest 16 cases which were histopathologically positive as lupus vulgaris, prurigo nodularies,post -kala-a -zar dermal leishmaniasis, erythema nodosum, mycosis fungoides were diagnosed negative by FNAC . Overall accuracy of FNAC was only $46.7 \%$.

Conclusions : FNAC has significant limitation for diagnosis of papulonodular skin disease and not a good alternative to histopathology in diagnosis of papulonodular skin disease.

Keywords : Fine needle aspiration cytology (FNAC), Papulo-nodular skin lesion and Histopathology.

\section{Introduction}

Fine needle aspiration cytology (FNAC) is a simple, safe, cost effective, quick, less painful minor surgical procedure and easily repeatable diagnostic method for obtaining a tissue diagnosis of subcutaneous and other tumours. ${ }^{1,2}$ The method is used most commonly for the preoperative assessment of lumps, but it is also applicable to lymph nodes, thyroid and neck masses with the aid of a special needle. ${ }^{3,4}$ In this technique, a thin, hollow needle is inserted into the mass for sampling of cells that, after being stained, will be examined under a microscope. In FNAC significant complications are usually rare, depending on the body site. Common complications include bruising and soreness. There is a risk, because the biopsy is very small (only a few cells), that the problematic cells will be missed and it does not preserve its histological architecture, resulting in a false negative result. ${ }^{5}$

For histopathological examination tissue should be obtained by major surgical (excision or open) biopsy. Histopathologic examination allows the tumor cells to be examined and also allows the pathologist to see architectural changes such as gland formation (differentiation), basement membranes, supporting connective tissue, blood vessels and the relationship between these and the tumor cells (can tell if the tumor is invasive or in-situ). Tissue changes give a more complete picture. ${ }^{6,7}$

FNAC as a diagnostic method has multiple significances. During the initial stage, it can be assessed whether the case is an inflammatory process or a neoplasm. If the diagnosis of a tumour growth is confirmed, a cytological test of the lymph nodes could provide information on the stage, prognosis, and the presence of metastases. ${ }^{8}$ In cases of postoperative recurrence, the consequent cytological test could quickly and precisely indicate the need for further interventions. ${ }^{9}$

A definitive specific diagnosis may not be possible by cytology in a proportion of cases, but a categorisation of disease and a differential diagnosis with an estimate of probability can usually be provided to suggest the most efficient further investigations, saving time and resources. ${ }^{10}$

The correlation between cytological and histological testing in the diagnosis of papulo-nodular skin lesions has been studied by a very small number of researchers. FNAC is not yet used as an alternate to histopathology for diagnosis of papulo-nodular Skin Lesions.

\section{Methods and materials}

A prospective study was carried out in the department of Dermatology \& Venereology and department of Pathology at Bangabandhu Sheikh Mujib Medical University, Dhaka. This study was conducted from March 2012 to August 2012 for a period of six (06) months. Thirty (30) patients were enrolled following inclusion criteria. Inclusion criteria's were patients of any age and both sexes presented with papulo nodular skin lesion of more than six weeks duration, involving any accessible body surface area, who gave consent and willing to comply with the study procedure. The sampling technique was purposive sampling. The patients were voluntarily included in the study with their consent and they were neither supported nor additionally burdened financially. 


\section{Study Procedure}

The demographic profiles including age, sex, education, profession were recorded. FNAC as well as the histopathology were performed in all patients. Data collection was conducted by the principal researcher. All data were compiled and edited meticulously by thorough checking and rechecking. All omissions and inconsistencies were corrected and were removed methodically. The entire collected data was compiled on a master chart first and then statistical analysis of the results were obtained by using window based computer software devised with Statistical Packages for Social Sciences (SPSS-17) (SPSS Inc, Chicago, IL, USA). The accuracy test of FNAC was measured by comparing with the histopathology as gold standard. Prior to the commencement of this study, the study protocol was approved by the Bangladesh College of Physicians and Surgeons (BCPS).

\section{Results}

A total number of 30 patients presented with popular-nodular skin lesions were included in this study. Figure 1 shows the distribution of patients according to age group. Among 30 patients less than and equal 20 years is $9(30.0 \%)$ cases, $14(46.7 \%)$ cases in group $21-40$ years, $3(10.0 \%)$ cases in group $41-60$ years and $4(13.3)$ cases are more than 60 years. The mean \pm SD is $32.7 \pm 18.2$ with a range of 12 - 70. Figure 2 shows the distribution of patients according to sex. Female is predominant than male which is $17(56.7 \%)$ cases and 13 $(43.3 \%)$ cases respectively. The male and female ratio is $1: 1.31$. Table I shows the distribution of patients according to education and occupation. Among 30 cases 5 (16.7\%) were illiterate, 16 (53.3\%) cases were primary educated, $5(16.7 \%)$ cases completed SSC, 2 (6.7\%) cases completed HSC and $2(6.7 \%)$ cases were graduated. Among 30 cases $5(16.7 \%)$ cases were in service, $13(43.3 \%)$ cases were housewife, $9(30.0 \%)$ cases were student and $3(10.0 \%)$ cases were labourer.

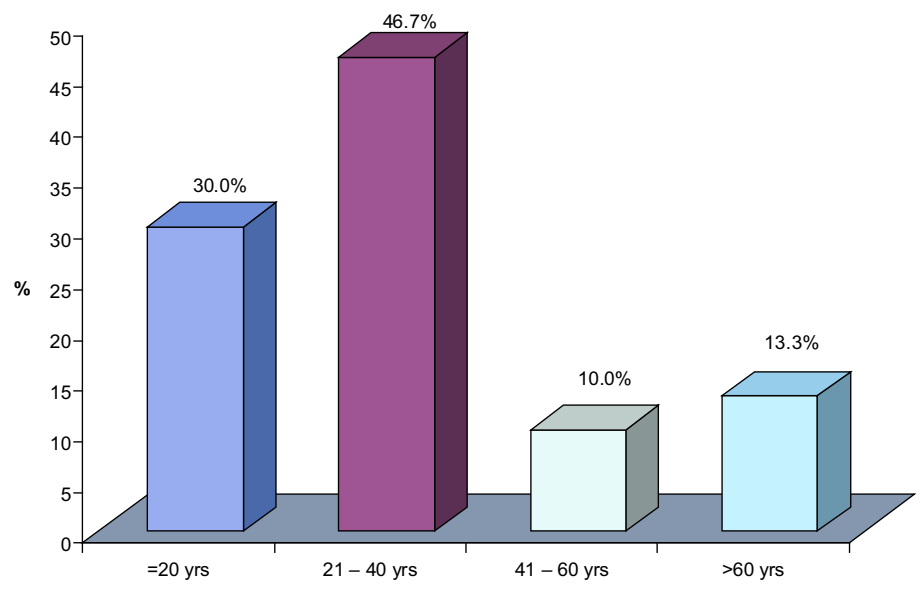

Figure 1: Distribution of patients according to age group

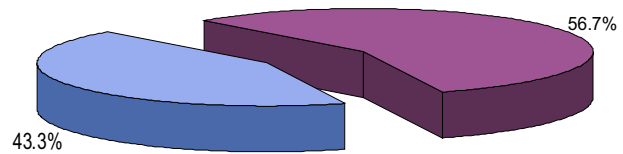

$\square$ Male $\square$ Female

Figure 2: patients according to sex
Table I: Distribution of patients according to education and occupation

$\begin{array}{lcc}\text { Education } & \text { Frequency } & \text { Percent } \\ \text { Illiterate } & 5 & 16.7 \\ \text { Primary School } & 16 & 53.3 \\ \text { SSC } & 5 & 16.7 \\ \text { HSC } & 2 & 6.7 \\ \text { Graduate \& Above } & 2 & 6.7 \\ \text { Occupation } & \text { Frequency } & \text { Percent } \\ \text { Service } & 5 & 16.7 \\ \text { Housewife } & 13 & 43.3 \\ \text { Student } & 9 & 30.0 \\ \text { Labourer } & 3 & 10.0\end{array}$

Table II shows the comparison of cytopathology (FNAC) with histopathology in diagnosis of papulo-nodular skin lesions. All the cases histopathologically diagnosed as epidermal inclusion cyst, pilar cyst and lipoma were diagnosed positive by FNAC and these were $5(100 \%)$ cases, $2(100 \%)$ cases and $7(100 \%)$ cases respectively. All the histopathological positive lupus vulgaris, prurigo nodularis, PKDL, erythema nodosum and mycosis fungoides were negative during diagnosed by FNAC. Table III showed the comparison of accuracy of histopathology and FNAC in diagnosis of papulo-nodular skin lesions. Accuracy of FNAC is $46.7 \%$ and histopathology was $100 \%$.

Table II: Comparison of cytopathology (FNAC) with histopathology in diagnosis of papulo-nodular skin lesions $(n=30)$

\section{FNAC Findings}

Histopathology

Positive cases Negative cases Accuracy

$\begin{array}{llll}\text { Epidermal inclusion cyst } & 5 & 0 & 100.0\end{array}$

$\begin{array}{llll}\text { Pilar Cyst } & 2 & 0 & 100.0\end{array}$

$\begin{array}{llll}\text { Lipoma } & 7 & 0 & 100.0\end{array}$

$\begin{array}{llll}\text { Lupus vulgaris } & 0 & 5 & 0.0\end{array}$

$\begin{array}{llll}\text { Prurigo nodularis } & 0 & 6 & 0.0\end{array}$

$\begin{array}{llll}\text { PKDL } & 0 & 2 & 0.0\end{array}$

$\begin{array}{llll}\text { Erythema nodosum } & 0 & 2 & 0.0\end{array}$

$\begin{array}{llll}\text { Mycosis Fungoides } & 0 & 1 & 0.0\end{array}$

$\begin{array}{llll}\text { Total } & 14 & 16 & 30\end{array}$

Table III: Comparison of accuracy of histopathology and FNAC in diagnosis of papulo-nodular skin lesions $(n=30)$

Procedure True positive True negative False positive False negative Accuracy

$\begin{array}{lrrrrr}\text { FNAC } & 14 & 0 & 0 & 16 & 46.7 \% \\ \text { Histopathology } & 30 & 0 & 0 & 0 & 100 \%\end{array}$




\section{Discussion}

A total number of 30 patients presented with papulo-nodular skin lesions were included in this study. The finding of this study showed that the middle age group of the people were most commonly affected by papulo-nodular skin lesions and the patients from $<20$ years to $>60$ years of age were included in this study which indicates that all age group of the people were more or less affected with papulo-nodular lesions. We found in this study that male patients were less commonly affected by papulo-nodular lesion though the ratio was more or less equal. Similar high proportion of female was reported by Soni et al and Ahmad et al. ${ }^{11,12}$ The distribution of patients according to education and occupation were recorded. The majority of the patients were less educated and the ignorance or unawareness may be the reason of the disease. On the other hand, as a profession amongst the study population, the housewife was most commonly affected group. There was no such study where the reason has been explained though it has been assumed that the most vulnerable group in the society are the women and reason may be negligence or lack of awareness of this high proportion.

The comparison of cytopathology (FNAC) with histopathology in diagnosis of papulo-nodular skin lesions were recorded in this study. All the cases which were histopathologically diagnosed as epidermal inclusion cyst, pilar cyst and lipoma were also diagnosed positive by FNAC and these were 5(100\%) cases, 2(100\%) cases and 7(100\%) cases respectively. All the histpathological positive lupus vulgaris, prurigo nodularis, PKDL, erythema nodosum and mycosis fungoides were negative during diagnosed by FNAC. The comparison of accuracy of histopathology and FNAC in diagnosis of papulo-nodular skin lesions was recorded. Accuracy of FNAC was $46.7 \%$ and histopathology was $100 \%$. Similar result was reported by Soni et al ${ }^{11}$ when evaluated the neck mass. The very important findings of this study was that lupus vulgaris, prurigo nodularis, PKDL, erythema nodosum and mycosis fungoides diagnosed positive by histopathologicaly only. FNAC showed various inflammatory cellular infiltrations in those cases. According to these findings FNAC showed significant limitation for the diagnosis of the papulo-nodular lesions of the skin. Any confusion in FNAC report should be evaluated by histopathology. Ahmad et al explained in his study on the efficacy of FNAC among the patients presented with cutaneous mass in the neck and found a very high accuracy result which was dissimilar with the present study. ${ }^{12}$ The reason was that multiple cutaneous diseases manifest as papulo-nodular lesions in different part of the skin which lead to multi-dimensional diagnosis of the disease. On the other hand, that study had fixed the criteria of the neck mass concisely and very little differential diagnosis had been reported.

\section{Conclusion}

The findings of this study permit to conclude that among the papulonodular skin lesions, the cases which were diagnosed histopathologically as epidermal inclusion cyst, pilar cyst and lipoma are also diagnosed positive by FNAC. However, cases which were diagnosed histopathologically as Lupus vulgaris, Prurigo nodularis, PKDL, Erythema nodosum and Mycosis Fungoides were negative during diagnosis by FNAC. Therefore, FNAC has significant limitations for diagnosis of papulo-nodular skin lesions and FNAC cannot be a good alternative in comparison to histopathology.

\section{References}

1. Lever J, Trott $P$, Webb A. Fine needle aspiration cytology. Journal of clinical pathology 1985; 38(1): 1-11.

2. Dennison G, Anand R, Makar SH, Pain JA. A prospective study of the use of fineâ $\square \square$ needle aspiration cytology and core biopsy in the diagnosis of breast cancer. The breast journal 2003;9(6):491-493

3. Payne R, Wilkinson JD, McKee PH, Jurecka W, Black MM. Nodular prurigo - a clinico-pathological study of 46 patients. Br J Dermatol 1985; 113: 431-9.

4. Franzen S, Zajicek J. Aspiration biopsy in the diagnosis of palpable lesions of the breast. Acta Radiol 1968;7:241-62.

5. Fogelson SK, Dohil MA. Papular and Nodular Skin Lesions in Children. Semin Plast Surg 2006;20:180-191.

6. Kocjan G, Feichter G, Hagmar B, Kapila K, Kardum-Skelin I, Kloboves V, et al. Fine needle aspiration cytology: a survey of current European practice. Cytopathology 2006;17(5):219-226.

7. Costache M, Ene AM, Simionescu O, Sajin M. Histopathological diagnosis of cutaneous vascular sarcomas. Romanian Journal of Morphology and Embryology 2010;51(1):105-109.

8. Soter NA. Nummular eczema and lichen simplex chronicus/prurigo nodularis. In: Freedberg IM, Eisen AZ, Wolff K, Austen KF, Goldsmith LA, Katz SI (eds). Fitzpatrick's Dermatology in General Medicine. New York: McGraw-Hill Companies, 2003; 1194-7.

9. http://www.indepreviews.com/article/2011/vol-13-no-1/006-084-FINE-NEEDLEASPIRATION-CYTOLOGY-\%28F-N-A-C\%29.pdf

10. Derek $E$ Roskell Ian $D$ Buley Fine needle aspiration of hepatic colorectal metastases BMJ. 2004 July 31; 329(7460): 244-245.

11. Soni S, Pippal SK, Yashveer B, Srivastava P. Efficacy of Fine Needle Aspiration Cytology in Diagnosis of Neck Masses. 2010;3(1):23-30.

12. Ahmad T, Naeem M, Ahmad S, Samad A, Nasir A. Fine needle aspiration cytology (FNAC) and neck swellings in the surgical outpatient. J Ayub Med Coll Abbottabad 2008;20(3):30-32. 